\title{
Diabetes Mellittus and the Risk of Cancer Formation - Possible Link and Review of Literature
}

\author{
Ekpe, Ekpe Lawson ${ }^{1}$, Omotoso Ayodele Joshua ${ }^{2}$ \\ ${ }^{1}$ Department of Chemical Pathology, University of Calabar, Calabar, Nigeria \\ ${ }^{2}$ Department of Pathology, University of Calabar, Calabar, Nigeria
}

Email address:

Lawsonekpe2002@yahoo.com (Ekpe, E. L.)

\section{To cite this article:}

Ekpe, Ekpe Lawson, Omotoso Ayodele Joshua. Diabetes Mellittus and the Risk of Cancer Formation - Possible Link and Review of Literature. American Journal of Internal Medicine. Vol. 3, No. 4, 2015, pp. 180-184. doi: 10.11648/j.ajim.20150304.15

\begin{abstract}
Background: The incidence of cancer is increased in patients with Type 2 diabetes mellitus. The aetiology is not exactly known. Various studies have been done to ascertain this fact. Aim: The aim of this study was to access the correlation between cancer and diabetes mellitus. Method: Using internet search, a comprehensive literature review was done and words such as diabetes mellitus, cancer, breast, pancreas, colorectal, prostate, liver, were searched from google scholar, yahoo, pubmed, medline, web MD to check for various articles published on this subject. The references of the relevant articles were also searched. Results: Analyses of results of various studies were considered and their RR were noted to access the correlation between cancer and diabetes mellitus. Conclusion: There is an increased fold rise of various cancers among type 2 diabetes mellitus patients.
\end{abstract}

Keywords: Cancer, Diabetes Mellitus, Breast, Liver, Prostate, Pancreas, Odds Ratio

\section{Introduction}

According to the International Diabetes Federation, about 366 million people had diabetes mellitus (DM) in 2011, and it is expected that this number may increase to 552 million by $2030^{1}$. The prevalence of diabetes has been put at $8.3 \%$ by some researchers ${ }^{2}$.DM is considered to be one of the major public health challenges ${ }^{3}$. The prevalence of Type 2 $\mathrm{DM}$ is considered to be about $2-10 \%$ in industrialized countries $^{4,5,6}$.

Recent evidence suggest that DM could also contribute to the initiation and propagation of certain cancers ${ }^{7}$. The link between cancer and diabetes has been investigated extensively and almost but not all studies, conclude that DM is associated with increased rate of several types of cancer ${ }^{8}$.While it is widely recognized that DM is associated with a high risk of cardiovascular and microvascular complications ${ }^{9}$, it is becoming increasingly associated with increased rate of cancer, based on several studies done and the link is independent of its association with obesity ${ }^{9}$. The correlation was first observed as far back as 1932 ${ }^{10,11}$. Though while cancer and DM are both common conditions, there are more commonly co-diagnosed in the same individual than will be expected ${ }^{12}$. Hence, if DM is associated even with a small increase in the risk of cancer and this may have important consequences at the population level ${ }^{8}$. This is particularly important because DM poses a worldwide public health crisis affecting both developed and developing countries ${ }^{13}$.

In this article, the authors aim to review valuable data suggesting a link between DM and risk of cancer in type 2 DM. The strength/motivation of this article is to review the various findings and contributions of various researchers with the view to acting on the available data to access the link (if any) between DM and cancer. Since the incidence of both cancer and diabetes are on the increase, this study is highly important.

\section{Cancer Risk in Patients with Diabetes Mellitus}

Strong link of diabetes and cancer are well noted. Huxley et al found out that there is an increased incidence of pancreatic cancer among patients with DM. The highest risk of DM linked with cancer have been noted for liver and pancreas $^{3,8}$. 


\section{Diabetes Mellitus and the Risk of Pancreatic Cancer}

Several meta-analyses show that the strongest link between DM and increased cancer is that of pancreatic cancer Huxley et al considered the link between type 2DM and the incidence of increase of pancreatic cancer. This involved 36 studies (17 case controls and 19cohort studies) over a period of 39 years using a computer based literature search. They concluded in their study that there is a strong association between type $2 \mathrm{DM}$ and pancreatic cancer. The relative risk (RR) was 1.82 for the combined odds ratio, $(95 \%$ confidence interval(CI),1.66-1.89) ${ }^{13}$. Stevens RJ et al did a similar study by conducting a systematic review of the risk of pancreatic cancer was 2.0(95 CI,1.37-3.01) $)^{14}$. Both type 1 and type $2 \mathrm{DM}$ increased the risk of pancreatic cancer by 1.5 to 2 fold increased rate ${ }^{13,16}$. The incidence of increased cancer of pancreas in DM affect both sexes.

\section{Diabetes and the Risk of Colorectal Cancer}

It has been hypothesized that DM may be a risk factor for colorectal cancer ${ }^{18}$. Several studies have been done to establish a correlation between DM and increasing cancer. Larson $\mathrm{C}$ et $\mathrm{al}$, in a meta- analysis of DM patients with colorectal cancer included a total of 15 studies involving 9 cohorts and 6 case controls with about 2.6 million people over a period of 39 yrs. Relevant articles were obtained by literature search of Medline. A total of 26,306 cases were found involved in their study. It was found that DM was associated with increased incidence of colorectal cancer were compared to non -diabetic patients. RR was $1.30,(95 \% \mathrm{CI}, 1.25-1.40)$. The result tallied with the research obtained both in the USA and Europe and there was no statistical differences by sex (RR was 1.33 , 95\%CI,1.231.44), while RR among men was $1.29,95 \% \mathrm{CI}, 1.15-1.44)^{12}$. Mortality was also increased in DM patients with colorectal cancer. Peters PJ et al also conducted a study to access the risk of colorectal cancer, using a total of 2759 cases of colorectal cancer. Type $2 \mathrm{DM}$ was associated with 1.30 fold increased risk of colorectal cancer (RR of 1.26 , 95\%CI, 1.18$1.33)^{20}$.Similarly, Hu FB et al did a 18 year old follow up in their study involving women. The RR was $1.43,95 \mathrm{CI}, 1.10$ $1.87, p<0.0 o 1$. There was a high correlation between DM and colorectal cancer. Also Larson SC, and Giovannuci did a large study involving 48,850 men in Sweden. Data analysis of this questionnaire-based study showed that DM was associated with a significant increased risk of both colon or rectal cancer $^{22}$. Peters PJH, et al also conducted a study to access the risk of colorectal cancer among diabetes patients. Using a total of 2759 cases, type $2 \mathrm{DM}$ was associated with 1.30 fold increased risk of colorectal cancer (RR was $1.26,95 \% \mathrm{CI}, 1.18$ $1.33){ }^{20}$.Similarly, Hu FB et al did a 18 year old follow up in their study involving women. The RR was $1.43(95 \% \mathrm{CI}, 1.10$ $1.87), p<0.005$. There was a high correlation between $\mathrm{DM}$ and colorectal cancer. Also Larson SC and Giovannuci did a large study involving 48,850 men in Sweden. Data analysis of this questionnaire-based study showed that there was increased risk of both colon or rectal cancer among DM patients ${ }^{22}$.

\section{Diabetes and the Risk of Liver Cancer}

Many studies emphasis that the highest risk of DM with cancer are associated with liver and pancreatic cancer ${ }^{3,24,25}$. Evidence has shown from studies that the relative risk of hepatocellular carcinoma are particularly high soon after diagnosis of diabetes mellitus ${ }^{26,27}$. Another study concluded that metastastic disease is more common at presentation of liver cancer among people with diabetes than those without diabetes ${ }^{28}$. Wang $\mathrm{C}$ et al performed a systematic review and meta-analysis of cohort studies from 1966 to 2011. Using 25 cohort studies, 18 showed that DM was associated with an increased incidence of hepatocellular cancer $(R R=2.10$, 95\% CI:1.60-2.51) compared with individuals without DM. The increased incidence of this was independent of geographical location, alcohol consumption, history of cirrhosis, infection with hepatitis $\mathrm{B}$ or $\mathrm{C}$ virus. In addition, DM was associated with increased hepatocellular carcinoma(HCC) mortality (RR: 1.56(95\%CI,1.30-1.87). These finding strongly suggest a positive association between DM and increased risk of HCC in both males and females ${ }^{24}$. The author found no publication bias ${ }^{24}$.An analysis of linked data from Medicare and Surveillance, Epideminology and EndResults(SEER) database in the US for 5607 people with liver cancer found that DM was present in $34 \%{ }^{20}$. Davila JA et al studied 2061 HCC patients and 6186 non-cancer controls. They found that the population of HCC patients with diabetes (43\%) was significantly greater than non-cancer controls (19\%). Also diabetes was associated with a 2-3 fold increase in the risk of $\mathrm{HCC}$, regardless of the presence of other major HCC risk factors ${ }^{30}$. El-Serag also concluded that diabetes increased the risk of chronic liver disease(CLD) and HCC. The RR was $1.98(95 \% \mathrm{CI}, 1.88-2.09)$ for CLD and RR of 2.16 (95\%CI,1.862.52) for hepatocellular cancer. $P<0.001$ for both cases ${ }^{31,32}$.

\section{Diabetees Mellitus and Prostate Cancer}

The risk of prostate cancer is reportedly low from most studies. Though the association between DM and prostate is controversial, with many studies suggesting positive and negative associations. A large nationwide case control study in Sweden by Fall K et al shows that the overall risk of prostate cancer in men with type 2 DM was lower than in men without type 2 DM. This study involved 44,352 men with prostate cancer and 221, 495 controls over a period of 4years. The odd ratio(OR) was $0.80(95 \% \mathrm{CI}, 0.76-0.85)$. The risk was found to be decreased with longer disease duration. They was a decreasing risk of prostate cancer with increased levels of HbAlc $(\mathrm{P}<0.05)^{33}$. Similar finding was noted by Bansal D, et al in a detailed meta-analysis of published studies regarding this subject. A total of $45 \quad(29$ cohort and 16 case 
control )studies involving 8.1 million participants and 132,332 prostate cancer positive cases, detected an inverse relationship between type $2 \mathrm{DM}$ and cancer of the prostate; providing a strong evidence that type $2 \mathrm{DM}$ patients have low incidence of developing prostate cancer. The RR was 0.85 (95\%CI,0.80 0.92). Publication bias was not observeds ${ }^{34}$.

Turner EL et al also reported decreased risk of prostate cancer in their study ${ }^{35}$. Kasper and Giovannucci (2006 ), in a meta-analysis of 65 studies buttressed the fact that risk of developing prostate by DM patients was highly reduced. The RR was $0.84(95 \% \mathrm{CI}, 0.76-0.93)$. The $16 \%$ average decreased risk of developing prostate cancer is attributed to decreased testosterone levels in DM patients ${ }^{37}$. Hence DM patients have low levels of serum prostate specific antigesn ${ }^{38}$.

\section{Diabetes Mellitus and Risk of Breast Cancer}

The link of DM with breast cancer remains controversial ${ }^{39}$.
In their meta-analysis, Lead $\mathrm{S}$ et al involving 16 studies over a 10 year period supported the evidence that DM was associated with a $23 \%$ increased risk of breast cancer, especially in postmenopausal women ${ }^{39}$. The RR was $1.25(95 \% \mathrm{CI}, 1.20-1.29)$. DM also increases the mortality from breast cancer overall RR was $1.29(95 \% \mathrm{CI}, 1.31-1.58)^{39}$.

Michel $\mathrm{KB}$ in a subsequent study involving nurses also found out that there was an increased incidence of breast cancer among women with type 2 DM. Hazard ratio was 1.17 (95\%CI,1.01 - 1.35). However, the association was predominant among women with estrogen receptor positive breast cancer, RR of 1.22(1.01-1.47 $)^{40}$. Lipscombe LL et al in their study proposed that women with diabetes have higher breast cancer incidence and mortality. This cohort study found that breast cancer patients were more likely to present with advanced stage breast cancer than those without diabetes. Stage IV breast cancer adjusted odd ratio (AOR) was $1.16(95 \% \mathrm{CI}, 1.06-1.28)^{41}$. Table 1 below shows a summary of the various cancers linked to DM.

Table 1. Summary of various cancers linked with DM and their risk ratios

\begin{tabular}{|c|c|c|c|c|c|c|}
\hline$. \mathbf{S} / \mathbf{n}$ & Cancer type, author, year & Total cases & Case control & cohort & Type of study & Summary \\
\hline & PANCREATIC CANCER & & & & & \\
\hline 1. & Hurley 2005 & 39 & 17 & 19 & & \\
\hline 2. & Steven 2007 & 39 & & & Review/meta-analysis & RR2.00(95CI, 1.37-3.1) \\
\hline 3. & Ben Q et al 2011 & & & & & RR1.82 (95CI, 1.66-1.89) \\
\hline 4. & Pezzili Raffael et al & & & & & \\
\hline 5. & Everhert et al & 20 & 9 & 11 & & RR 2.1 (95CI, 1.60-2.80) \\
\hline \multirow[t]{2}{*}{6.} & Dongui Li et al 2015 & & & & & \\
\hline & COLORECTAL CANCER & & & & & \\
\hline 1 & Larson SC et al 2005 & 15 & 9 & 6 & & RR $1.30(95 \mathrm{CI}), 1.20-2.80)$ \\
\hline 2 & Peter PJH & & & & & \\
\hline \multirow[t]{2}{*}{3} & $H u F B$ & & & & & \\
\hline & LIVER CANCER & & & & & \\
\hline 1 & Wang et al & 25 & & & $\begin{array}{l}\text { Meta-analysis/systematic } \\
\text { review }\end{array}$ & RR 2.0 (95CI, 1.61-2.51) \\
\hline 2 & Davilla JA, et al & & & & & $\begin{array}{l}\text { RR 2.87(95\%CI, 2.40-3.30), } \\
p<0.001\end{array}$ \\
\hline \multirow[t]{4}{*}{3} & El-Serag et al 2004 & & & & & $\begin{array}{l}\text { RR1.98(95CI, 1.88-2.09), } \\
p<0.01 \text {-CLD }\end{array}$ \\
\hline & & & & & & $\begin{array}{l}\text { RR 2.10(95CI,1.86-2.52), } \\
p<0.0001-\mathrm{HCC}\end{array}$ \\
\hline & El-Serags & 26 & 13 & 13 & Systematic review & RR2.50(95CI, 1.8-3.5) \\
\hline & PROSTATE CANCER & & & & & \\
\hline 1 & Fall K et al 2013 & & & & Case - control & OR 0.80 (95CI, 6.76-0.85) \\
\hline 2 & Bansal D et al 2013 & 45 & 29 & 16 & Mata-analysis & RR 0.85 (95CI, 0.80-0.92) \\
\hline 3 & Turner EL et al 2010 & & & & Case control & OR 0.75 (95CI, 0.61-0.99) \\
\hline 4 & $\begin{array}{l}\text { Kasper et al } 2006 \\
\text { BREAST CANCER }\end{array}$ & 19 & 10 & 9 & Meta-analysis & RR 0.84 (95CI, 0.76-0.93) \\
\hline 1 & Liao et al & 16 & & & Meta-analysis & RR 1.25(95CI, 1.20-1.29) \\
\hline 2 & Michelle $K B$ & 26 & & & Systematic review & $\begin{array}{l}\text { Hazard ratio } 1.17(95 \mathrm{CI}, 0.01- \\
1.36)\end{array}$ \\
\hline \multirow[t]{3}{*}{3} & Lipscombe & & & & Cohort & $\begin{array}{l}\text { AOR stage IV RR1.16 }(95 \% \mathrm{CI} \text {, } \\
1.06-1.26\end{array}$ \\
\hline & BLADDER CANCER & & & & & \\
\hline & & & & & & RR 1.24(95CI, 1.08-1.42 \\
\hline 1 & Larson SC et al 2006 & 16 & & & Meta-analysis & $\begin{array}{l}\text { RR 1.35(95CI, 1.17-1.56), } \mathrm{P}<0 \text { - } \\
001\end{array}$ \\
\hline 2 & Zhu Z et al 2013 & 36 & 19 & 8 & Meta-analysis & $\begin{array}{l}\text { RR } 1.35 \text { (95CI, 1.17-1.56), } \\
p<0.001\end{array}$ \\
\hline
\end{tabular}




\section{Possible Pathophysiology of Cancer in Diabetes Mellitus}

Several possible explanations have been put forth to explain the increased risk of cancer in $\mathrm{DM}^{8}$. The cause of the association is not clear and remains the subject of different hypotheses ${ }^{11}$. The most frequently cited reason is the potential effect of insulin ${ }^{11}$. Insulin is found in high concentration in most patients with type $2 \mathrm{DM}$ ands this hormone is believed to express a mitogenic effect ${ }^{11}$. High levels of insulin, independent of body fat are linked to increased production of insulin-like growth factor 1(IGF-1) which shares a similar situation with insulin, playing a key role in cell growth, proliferation and the inhibition of apoptosis $^{42}$. DM is characterized by hyperglycemia and hyperinsulinemia with a reduced effect of insulin(insulin resistance in peripheral tissues).

Chronic hyperinsulinemia is a possible factor favouring cancer initiation and/or progression in DM patients due to the mitogenic effects of insulin ${ }^{8}$. First, when insulin level increases, insulin then binds and activates the related insulinlike growth factor (IGF - 1) receptor which shares about $80 \%$ homology with insulin receptor, but has a more potent mitogenic and transforming activity ${ }^{8}$. Also, insulin decreases IGF-1 binding proteins (IGF-1 BP1 and IGF-1 BP2). This will result in increased free IGF-1, the biological active form of the growth factor ${ }^{8}$. Secondly, many cancer cells have increased insulin receptors (IR) content ${ }^{43}$, which is expressed leading to mitogenic effects ${ }^{8}$. Finally, insulin mitogenic activities might be enhanced at the cellular level by post receptor molecular mechanisms.

Elevated plasma insulin is also associated with poor outcome of cancer and disease recurrence ${ }^{12}$. Insulin itself exerts a mitogenic effect in various tissues including breast cancer cell lines which are estrogen receptor positive ${ }^{12}$. In breast cancer insulin induces aromatase activity and reduces sex hormone binding globulin (SHBG) leading to increased free estrogen levels which in turn increases mitogenicity ${ }^{12}$. Also, breast cancer cells appear to have high levels of insulin receptors, compared to normal breast tissue ${ }^{44}$. Also studies have shown that people with circulatory IGF-1 have an increased risk of common epithelial cancer such as breast, colon and prostate ${ }^{45}$. Hyperinsulinemia also results in reduced levels of IGF-binding protein (IGFBP1), thus increasing the levels of bioactive IGF $-1^{8}$.

Other parameters linking DM and cancer are leptin and adiponectin which are both adipocytokines. There is some evidence that leptin may be involved in total invasion and metastasis of solid tissues. Studies have shown that adiponectin are associated with $40 \%$ reduction in the risk of development of type $2 \mathrm{DM}^{46}$.

Other factors that may influence the risk of cancer in diabetes are obesity, hyperglycemia, free fatty acids and chronic inflammations and oxidative stress ${ }^{8}$.
A recent emergency fact is anti-cancer therapy have been implicated in the formation of cancer in DM, while metformin ,an anti-diabetic drug has been linked to protect the bladder from cancer of the bladder in patients who use metformin in the management of type $2 \mathrm{DM}^{47}$.

\section{Conclusion}

There is an increased risk of cancer among DM patients. The incidence of cancer in DM patients is becoming increasingly higher than previously thought. Therefore managing physicians of cancer patients should never forget to assess and screen their patients for DM.

\section{References}

[1] Whiting DR, Guariguata L, Weil C, Shaw J: IDF diabetes atlas. Global estimate of the prevalence of diabetes for 2011 and 2030. Res Clin Pract. 94:311-321. 2011.

[2] Centers for disease control and prevention. National Diabetes fact sheet. 2011.

[3] Hermminski K, Li X, Sundquist J, Sundquist K. Risk of cancer following hospitalization for type 2 diabetes. The oncologist endocrinology 15: 548-555. 2010.

[4] Adeghate E, Schattner P, Dunn E. an update on the etiology and epidemiology of diabetes mellitus. Ann NY acad sci. 1084: $1-29,2006$.

[5] Hussain A, Claussen B, Ramachandran et al. Prevention of type 2 diabetes. Res Clin Pract. 76: 317-326. 2007.

[6] Ringborg A, Lindgren P, Martinell M, et al. Prevalence and incidence of type $2 \mathrm{~d}$ diabetes and the complications - 19962003- estimates from a Swedish population based study. Diabet Med 25: 1178-1186. 2008.

[7] Josh Sanket, Liu Morghan, Tuner Nigel. Diabetes and its link with cancer. Providing the fuel and spark to launch and aggressive growth regime. Biomed Research International. 2015 .

[8] Vigneri P, Frasca F, Sciacca L. Pandini G, Vigneri R. diabetes and cancer. Endocrine-Related Cancer 16: 1103-1123. 2009.

[9] Fowler MJ. Microvascular and macrovascular complications of diabetes. Clinical Diabetes.26(2):77-82.2008

[10] Smith U,Gale EM.Does Diabetes therapy influence the risk of cancer.Diabetetologia.52:1699-1708.2009s

[11] Czyzyk Artur, Szczepanik. Zdzislacva. Diabetes mellitus and cancer 11(5): 245-252. 2000.

[12] Chowdhury TA. Diabetes and cancer.QJM,103(12)903-915, 2010.

[13] Huxley R, Ansary-Morghaddan A, Gonzalez A., et al. Type 2 diabetes and pancreatic cancer : A meta-analysis of 36 studies. Br J cancer 92(11): 2076-83. 2005.

[14] Stevens RJ, Rouldam AW, Beral V. Pancreatic cancer in type 1 and young-onset diabetes. Systematic review and metaanalysis. Br J cancer 96(3): 507-509 - 2007. 
[15] Magruder JT, Anderson DK. Diabetes and pancreatic cancer: chicken or egg. Pancreas 40(3) 339-51. 2011.

[16] Everhart J, Wright D. Diabetes mellitus as a risk factor for pancreatic cancer. A meta-analysis - JAMA. : 273(20) 24-31.

[17] Muniraj T, Chin ST. Diabetes and Cancer.Minneaxa gastroenterol dietol. 58(4).

[18] Giovanucci E. Insulin and colon cancer. Cancer causes control. 6:164-79, 1995

[19] Larson SC, Orsini N, Wolk A. Diabetes mellitus and risk of colorectal cancer: A meta-analtysis. J Natl Cancer Inst. 97(22). 1679-87. 2005.

[20] Peters PJ, Bazelier MT, Leufkens HG, Frank V, Bruon ML. The risk of colorectal cancer in patients with type 2 diabetes. Association with treatment and obesity. Diabetes care. 2014.

[21] Hil FB, Mansin JE, Hanter D, Colditz CA, et al. Prospective study of adult onset DM (type 2) and risk of CRC in women. $J$ Natl. Cancer Inst. 91(6). 542-2. 1999.

[22] Larson SC, Giovanniuci E, Wolk A. Diabetes and colorectal cancer incidence in the cohort of Swedish man.

[23] Tolman KG, Funseca V, Dalpiaz A, Tan Merg. Spectrum of liver diseases in type $2 \mathrm{DM}$ and management of Patients with diabetes and liver disease. Diabetes Care 30(3): 734-743. 2007.

[24] Wang C, Wang X, Curg G, Ben Q, Qui W, Chen Y. et al. Increased risk of hepatocellular carcinoma in patients with diabetes mellitus: a systematic review with meta-analysis of cohort studies. Inst. J cancer 130:1639-1648. 2012

[25] Xhou XH, Qino Q, Zetherlius B, Pyrola K, Soderberg S, Payak A, et al. Diabetes, prediabetes and cancer mortality Diabetologia. 53: 1867-76, 2010.

[26] Johnson JA, Bowker SL, Richardson K, Marra CA. Timevarying incidence of cancer after the onset of type 2 diabetes: evidence of potential detection bias. Diabetologia 54:2263$2271,2011$.

[27] Carnestensen B, Witte DR, Frii ., Cancer occurrence in Danish diabetic patient: duration and insulin effect. Diabetologia 55: 948-958: 2012.

[28] Connolly GC, Safadjou S, Chen R, Nduaguba A, Dunre R, Khorana et al. Diabetes mellitus is a associated with the presence of metastatic spread at disease presentation in hepatocellular carcinoma.

[29] McGlynn KA, Quraishi S, Wetzel TM, Davilla JA, El-Serag HB.Diabetes increases the risk of hepatocellular carcinoma in the United States. Cancer Research 70(8): 1816;2010

[30] Darik JG, Morgan RO, Shaib Y, mcGlynn KA, El-Seragg HB. Diabetes increases the risk of hepatocellular carcinoma in the United States: a population based case control study. Gut 54(4)..533-9, 2005.

[31] El-Serag HB, Tran Top Everhart JE. Diabetes increase the risk of chronic liver disease and hepatocellular carcinoma. Gastroenterology 126(2): 460-468, 2004.

[32] El-Serag HB, Hampel H, Javadi F. The association between diabetes and hepatocellular carcinoma: a systematic review of epidermiological evidence. Clin gastroenterol hepatol 4(3):369-80: 2006.

[33] Fall K, Garmo H, Gudbjornsdottir S, Stattin P, Zetherlum B. Diabetes mellitus and prostate cancer; a nationwide case control study within PCBase Sweden. Cancer Epidemol Biomarkers. Prev. 22(6): 1102-9, 2013.

[34] Bansal D, Bhansali A, Kapli G, Undela K, Tiwon P. Type 2 $\mathrm{DM}$ and risk of prostate cancer: a meta-analysis of observational studies. Prostate cancer, prostatic dis. 16(2) 151-8. 2013.

[35] Turner EL, Lane JA, Donoran JL, et la. Association of diabetes mellitus with prostate cancer.. nested case-control study. Prostate testing for cancer and treatment study). Inst. Journal of cancer 128(2): 2010.

[36] Kasper JS, Giovannuci E. A meta-analysis of DM and the risk of prostate cancer. Cancer epidemiol biomarker of prevention 15(11): 2056-62. 2006

[37] Barrett Connar. Lower endogenous androgenic level and dyslipidemia in men with no insulin dependent diabetes mellitus. Am J of internal medicine 112: 807-811.1992.

[38] Werny DM, Saraija M, Greger. Prostate specific antigen values in diabetic and non diabetic US men. 2001-2002. Am J epidermiol 164:928-983.

[39] Liao S, L, J, Wei W, Wang L, Zhang Y, L, J, Wang C, Sun S. Association between diabetic and breast cancer risk: a metaanalysis of the literature. Asian Pac J Cancer Rev. 12(4): 1061-5. 2011

[40] Michael KB, Solomon CG, Hu FB, et al. Type 2 diabetes and subsequent incidence of breast cancer in the Nurses health study. Diabetes care: 26(6) 1752-1758. 2003.

[41] Lipscombe LL, Fischer HD, Austin PC, Fu L, et al. The association between diabetes and breast cancer stage of diagnosis: a population based study. Breast cancer research and treatment. 150(3): 613-620. 2015.

[42] Zhang H,Zhang C,Wu D. Activation of insulin-like growth factor 1 receptor regulates the radiation-induced lung cancer cell apoptosis.Immunobiology.2015

[43] Papa V, Pezzino V,Constantino A,Belfiore A, et al elevated insulin receptor content in human breast cancer. Journal of clinical investigation.86,1503-1510,1990

[44] Yu H, Rohan T. Role of the Insulin-Like Growth Factor Family in Cancer Development and Progression.J Natl Can Inst 92(18):1412-1489.2000

[45] Pollak MN. Insulin,insulin-like growth factor,insulin resistance and neoplasia..Am J clin Nutr. 86(3):82058215.2007

[46] Wannathee SG, Lowe GD, Rumley A.Diabetes care.30(5):1200-1205.2007.

[47] Zhang T,Zhang Y,Guo P, Xiong H. The Antidiabetic Drug Metformin Inhibits the Proliferation of Bladder Cancer Cells in Vitro and in vivo.Int J Mol Sci. 2013 Dec; 14(12): 2460324618. 